\title{
Regulation of virulence and $\beta$-lactamase gene expression in Staphylococcus aureus isolates: cooperation of two-component systems in bloodstream superbugs
}

\author{
Sanaz Dehbashi ${ }^{1}$, Hamed Tahmasebi ${ }^{2}$, Behrouz Zeyni ${ }^{1}$ and Mohammad Reza Arabestani ${ }^{1,3^{*}}$
}

\begin{abstract}
Background: Methicillin-resistant Staphylococcus aureus (MRSA)-bloodstream infections (BSI) are predominantly seen in the hospital or healthcare-associated host. Nevertheless, the interactions of virulence factor (VFs) regulators and $\beta$-lactam resistance in MRSA-BSI are unclear. This study aims to characterize the molecular relationship of twocomponent systems of VFs and the expression of the $\beta$-lactamase gene in MRSA-BSI isolates. In this study, 639 samples were collected from BSI and identified by phenotypic methods. We performed extensive molecular characterization, including SCCmec type, agr type, VFs gene profiles determinations, and MLST on isolates. Also, a quantitative real-time PCR (q-RT PCR) assay was developed for identifying the gene expressions.
\end{abstract}

Results: Ninety-one (91) S. aureus and 61 MRSA (67.0\%) strains were detected in BSI samples. The presence of VFs and SCCmec genes in MRSA isolates were as follows: tst (31.4\%), etA (18.0\%), etB (8.19\%), lukS-PVL (31.4\%), lukF-PV (18.0\%), lukE-lukD (16.3\%), edin (3.2\%), hla (16.3\%), hlb (18.0\%), hld (14.7\%), hlg (22.9\%), SCCmed (16.3\%), SCCmecll (22.9\%), SCCmecllI (36.0\%), SCCmeCIV (21.3\%), and SCCmecV (16.3\%). Quantitative real-time PCR showed overexpression of mecRl and mecl in the toxigenic isolates. Moreover, RNAIII and sarA genes were the highest expressions of MRSA strains. The multi-locus sequence typing data confirmed a high prevalence of CC5, CC8, and CC30. However, ST30, ST22, and ST5 were the most prevalent in the resistant and toxigenic strains.

Conclusion: We demonstrated that although regulation of $\beta$-lactamase gene expressions is a significant contributor to resistance development, two-component systems also influence antibiotic resistance development in MRSA-BSI isolates. This indicates that resistant strains might have pathogenic potential. We also confirmed that some MLST types are more successful colonizers with a potential for MRSA-BSI.

Keywords: Methicillin-resistant Staphylococcus aureus, Virulence factors, $\beta$-Lactamase, Antibiotic resistance

\footnotetext{
* Correspondence: mohammad.arabestani@gmail.com

${ }^{1}$ Microbiology Department, Faculty of Medicine, Hamadan University of Medical Sciences, Hamadan, Iran

${ }^{3}$ Nutrition health Research center, Hamadan University of Medical Sciences, Hamadan, Iran

Full list of author information is available at the end of the article
}

(c) The Author(s). 2021 Open Access This article is licensed under a Creative Commons Attribution 4.0 International License, which permits use, sharing, adaptation, distribution and reproduction in any medium or format, as long as you give appropriate credit to the original author(s) and the source, provide a link to the Creative Commons licence, and indicate if changes were made. The images or other third party material in this article are included in the article's Creative Commons licence, unless indicated otherwise in a credit line to the material. If material is not included in the article's Creative Commons licence and your intended use is not permitted by statutory regulation or exceeds the permitted use, you will need to obtain permission directly from the copyright holder. To view a copy of this licence, visit http://creativecommons.org/licenses/by/4.0/ The Creative Commons Public Domain Dedication waiver (http://creativecommons.org/publicdomain/zero/1.0/) applies to the data made available in this article, unless otherwise stated in a credit line to the data. 


\section{Background}

Bacteremia is defined as the presence of bacteria in the blood and may be detected by blood culture analysis for particular bacterial microbes [1, 2]. Traditionally methicillin-resistant Staphylococcus aureus (MRSA)bloodstream infection (BSI) has been regarded as only a hospital-acquired infection (HAI) [3, 4]. Following the extensive use of a new antibiotic, a small number of MRSA successfully develop drug resistance. They develop mutations in the genome or resistant genes $[2,5]$. Thus, new strains of bacteria resistant to existing antibiotics are developed and referred to as superbugs [6]. Multidrug resistance (MDR) was defined as nonsusceptibility to at least one antibiotic in three or more antibiotic groups. Extensive drug resistance (XDR) was defined as non-susceptibility to at least one antibiotic in all except two or fewer groups, and pan drugresistance (PDR) was defined as non-susceptibility to all antibiotics in all groups [6, 7].

The principal and most significant difference between methicillin-susceptible and MRSA is the gene cassette embedded in the chromosome, also known as staphylococcal chromosomal cassette mec (SCCmec) [8]. The main element of SCCmec is the mecA gene, which ensures that the host is resistant to known $\beta$-lactams [9]. S. aureus also expresses a wide array of virulence factors that provide survival during infection. The agr locus regulates more than 70 genes, including 23 virulence genes [10, 11]. It contains two divergent promoters, P2 and P3. The P2 promoter drives transcription of an auto-inducing signal transduction module composed of four genes, agrBDCA [10], which further activates transcription from the P2 and P3 promoters and completes the auto-inducing circuit $[10,12]$.

In addition to two-component systems, several global transcriptional regulators function in $S$. aureus virulence factors [12]. Nevertheless, several global regulatory systems have been identified in $S$. aureus, including the staphylococcal accessory regulator A (sarA). SarA has initially been thought to antagonize the effect of agr but later was found to have an additive effect. Mutations in either agr or sarA attenuate virulence; however, agr-sarA double mutant leads to the loss of virulence $[10,12,13]$. Moreover, the two-component system SaeRS is transcribed from a four-gene operon, further encoding the auxiliary genes saeP and saeQ [14].

While limited information is available regarding the risk for BSI among minority patients, there is no clear information regarding the associations of two-component systems and the expression of the $\beta$-lactamase gene in MRSA-BSI. Therefore, the primary aim of this investigation was to characterize and determine the risk factors for patients with BSI. A secondary purpose was to assess sequence types and clonal complex of superbugs in patients with MRSA-associated BSI.

\section{Results}

Out of 639 BSI samples, 91 (14.2\%) S. aureus was isolated. Also, $53(58.2 \%)$ and $38(41.7 \%)$ isolates were collected from female and male patients.

\section{Antibiotics susceptibility patterns}

Antibiotic resistance pattern information is presented in Table 1. Out of 91 isolates of S. aureus, 83 (91.2\%) isolates were sensitive to linezolid. Moreover, 74 (81.3\%) and $61(67.0 \%)$ isolates were resistant to penicillin and cefoxitin, respectively. Fifty (54.9\%) isolates were resistant to at least seven antimicrobials and considered as MDR strain.

\section{The prevalence of virulence and $\mathrm{SCCmec}$ genes}

Based on Table 1, out of 91 isolates of S. aureus, 9 (15.7\%) isolates carry all virulence and SCCmec genes and are considered superbug strains. Among 61 MRSA strains, SCCmecIII (36.3\%) and SCCmecIV (21.3\%) types were the most common. Moreover, the frequency of VFs genes in MRSA strains was as follows: tst, and lukS-PVL genes in 19 isolates (31.4\%), hlg in 14 isolates (22.9\%), and etA, $l u k F-P V$, and $h l b$ genes in 11 isolates (18.0\%). None of the methicillin-susceptible Staphylococcus aureus (MSSA) strains carried the VF genes.

\section{Molecular analysis of $\beta$-lactamase and virulence regulatory genes}

The results of the expression analysis of $\beta$-lactamase and virulence regulatory are shown in Fig. 1. Downregulation for the SaeRS, sarA, and RNAIII genes was observed in antibiotic-sensitive isolates. Moreover, $\beta$ lactamase regulatory genes indicated the highest expression levels in virulent isolates. Interestingly, agr locus did not antagonize mecA, mecI, and blaZ genes in the MRSA strains. In total, these data suggest that agr locus acts as a regulatory bridge between antibiotic resistance and virulence factor production in $S$. aureus. Also, for the overexpression of sarA, RNAIII, SaeRS genes, the high expression was seen in superbug isolates.

\section{Analysis of hit-map tree of gene expression}

The comparison of expression level for the virulence and $\beta$-lactamase regulatory genes in all 91 isolates of $S$. aureus is depicted in Fig. 1. The heat-map reflects the correlation between the virulence and $\beta$-lactamase regulatory genes in different strains. Compared to the control, a high-expressions of agr locus, sarA and SaeRS were found in MRSA and virulent strains. Also, in MRSA and MSSA strains, the RNAII and RNAIII genes had different expressen. Furtehr, the mecRI, and mecI regulatory genes were significantly more expressed in 
Table 1 Frequency of antibiotic resistance, virulence factors, and SCCmec types, in BSI collection of MRSA and MSSA strains

\begin{tabular}{|c|c|c|c|c|c|c|c|c|}
\hline \multirow[t]{2}{*}{ Antimicrobial agent } & \multicolumn{3}{|c|}{ MRSA $(n=61)$} & \multirow[t]{2}{*}{$P^{\#}$} & \multicolumn{3}{|c|}{ MSSA $(n=30)$} & \multirow[t]{2}{*}{$P^{\#}$} \\
\hline & $\mathbf{R}$ & I & $S$ & & $\mathrm{R}$ & I & $S$ & \\
\hline Cefoxitin & 61 & 0 & 0 & 0.004 & 0 & 0 & 30 & 0.025 \\
\hline Gentamycin & 38 & 8 & 16 & 0.03 & 1 & 0 & 29 & 0.012 \\
\hline Erythromycin & 19 & 16 & 6 & 0.03 & 0 & 0 & 30 & 0.025 \\
\hline Amikacin & 11 & 18 & 32 & 0.12 & 0 & 0 & 30 & 0.025 \\
\hline Ciprofloxacin & 33 & 12 & 16 & 0.021 & 0 & 0 & 30 & 0.025 \\
\hline Clindamycin & 19 & 13 & 29 & 0.022 & 0 & 0 & 30 & 0.025 \\
\hline Chloramphenicol & 8 & 16 & 37 & 0.65 & 7 & 0 & 23 & 0.65 \\
\hline Linezolid & 8 & 19 & 34 & 0.040 & 0 & 0 & 30 & 0.025 \\
\hline Daptomycin & 11 & 0 & 50 & 0.79 & 0 & 0 & 30 & 0.025 \\
\hline Penicillin & 61 & 0 & 0 & 0.001 & 13 & 9 & 8 & 0.059 \\
\hline Gatifloxacin & 40 & 11 & 12 & 0.025 & 9 & 1 & 20 & 0.025 \\
\hline Trimethoprim/sulfamethoxazole & 11 & 0 & 50 & 0.82 & 0 & 0 & 30 & 0.025 \\
\hline MDR & 56 & & & 0.051 & 4 & & & 0.95 \\
\hline $\mathrm{XDR}$ & 24 & & & 0.072 & 0 & & & - \\
\hline PDR & 8 & & & 0.22 & 0 & & & - \\
\hline \multicolumn{9}{|l|}{ SCCmec types } \\
\hline sccmed & 10 & & & 0.019 & 0 & & & - \\
\hline sccmedl & 14 & & & 0.041 & 0 & & & - \\
\hline sccmedll & 24 & & & 0.020 & 0 & & & - \\
\hline scCmedV & 13 & & & 0.008 & 0 & & & - \\
\hline sccmecV & 10 & & & 0.045 & 0 & & & - \\
\hline \multicolumn{9}{|l|}{ Virulence factor genes } \\
\hline tst & 19 & & & 0.021 & 0 & & & - \\
\hline etA & 11 & & & 0.001 & 0 & & & - \\
\hline$e t B$ & 5 & & & 0.071 & 0 & & & - \\
\hline lukS-PVL & 19 & & & 0.035 & 0 & & & - \\
\hline lukF-PV & 11 & & & 0.040 & 0 & & & - \\
\hline lukE-lukD & 10 & & & 0.055 & 0 & & & - \\
\hline edinA & 2 & & & 0.037 & 0 & & & - \\
\hline hla & 10 & & & 0.111 & 0 & & & - \\
\hline$h / b$ & 13 & & & 0.018 & 0 & & & - \\
\hline hld & 9 & & & 0.068 & 0 & & & - \\
\hline hlg & 14 & & & 0.018 & 0 & & & - \\
\hline
\end{tabular}

S Susceptible, $R$ Resistant, I Intermediate; " Statistical relationship between chi-square test between different variables with significant level $\leq 0.05$

MRSA, toxigenic and hemolysin positive strains as compared to MSSA and non-virulent strains.

When comparing expression of blaZI and mecA genes to controls, the largest difference was found in the toxigenic and hemolysin positive strains, and the nonvirulent strains. Indeed, most of the agr locus and SaeRS genes were expressed deficiently in non-toxigenic and MSSA strains. Also, mecRI and mecI regulatory genes are overexpressed in the toxigenic isolates.

\section{Analysis of MLST dendrogram phylogenic tree}

The neighbor-joining tree based on nucleotide difference in sequence data of each housekeeping gene was constructed, as shown in Fig. 2. Sequencing of housekeeping genes of all 91 representative isolates of $S$. aureus showed seven CC and 64 unique STs. However, the ST30, ST22, and ST8 were the most common STs in S. aureus isolates. These three STs also showed the highest frequency in MDR, $\mathrm{XDR}$, and PDR strains. Also, most of the SCCmec types 





(See figure on previous page.)

Fig. 1 Differential expression of virulence and $\beta$-lactamase regulatory genes in BSI isolates of S. aureus. a: Heatmap of virulence and $\beta$-lactamase regulatory genes expression patterns in all $91 \mathrm{~S}$. aureus. Red represents up-regulation and blue down-regulation relative to control. b: The expression levels of $\beta$-lactamase regulatory genes in MDR, XDR, and PDR strains, discriminated based on $p$-value and $\log _{2}$ (fold-change) at an a level of 0.05 . c: The expression levels of $\beta$-lactamase regulatory genes in hemolysin producer, toxin producer, and non-virulent strains, discriminated based on $p$-value and $\log _{2}$ (fold-change) at an a level of 0.05 . $\mathbf{d}$ The expression levels of virulence regulatory genes in MDR, XDR, and PDR strains, discriminated based on $p$-value and $\log _{2}$ (fold-change) at an a level of 0.05 . e: The expression levels of virulence regulatory genes in hemolysin producer, toxin producer, and non-virulent strains, discriminated based on $p$-value and $\log _{2}$ (fold-change) at an a level of 0.05. Error bars standard errors: 0.05 . Student's t-test and Tow-Way ANOVA test were performed for testing differences between groups. *: $p<$ $0.05, * *: p<0.001,{ }^{* * *}: p<0.0001$

were found in five CC of $S$. aureus: CC5, CC8, CC22, CC30, and CC45.

\section{Relationship between VFs and antibiotic resistance}

The results of the statical analysis showed in Table 2 . However, the virulence profiles were significantly associated with the antibiotic resistance profile $(p \leq 0.05)$. No statistical association between the VFs prevalence and linezolid and amikacin resistance was detected. Surprisingly, a strong relationship was observed between expression levels of virulence and $\beta$-lactamase regulatory genes $(p \leq 0.001)$. Further, a high prevalence of SCCmec was significantly detected in toxigenic and hemolysin positive isolates $(p \leq 0.05)$.

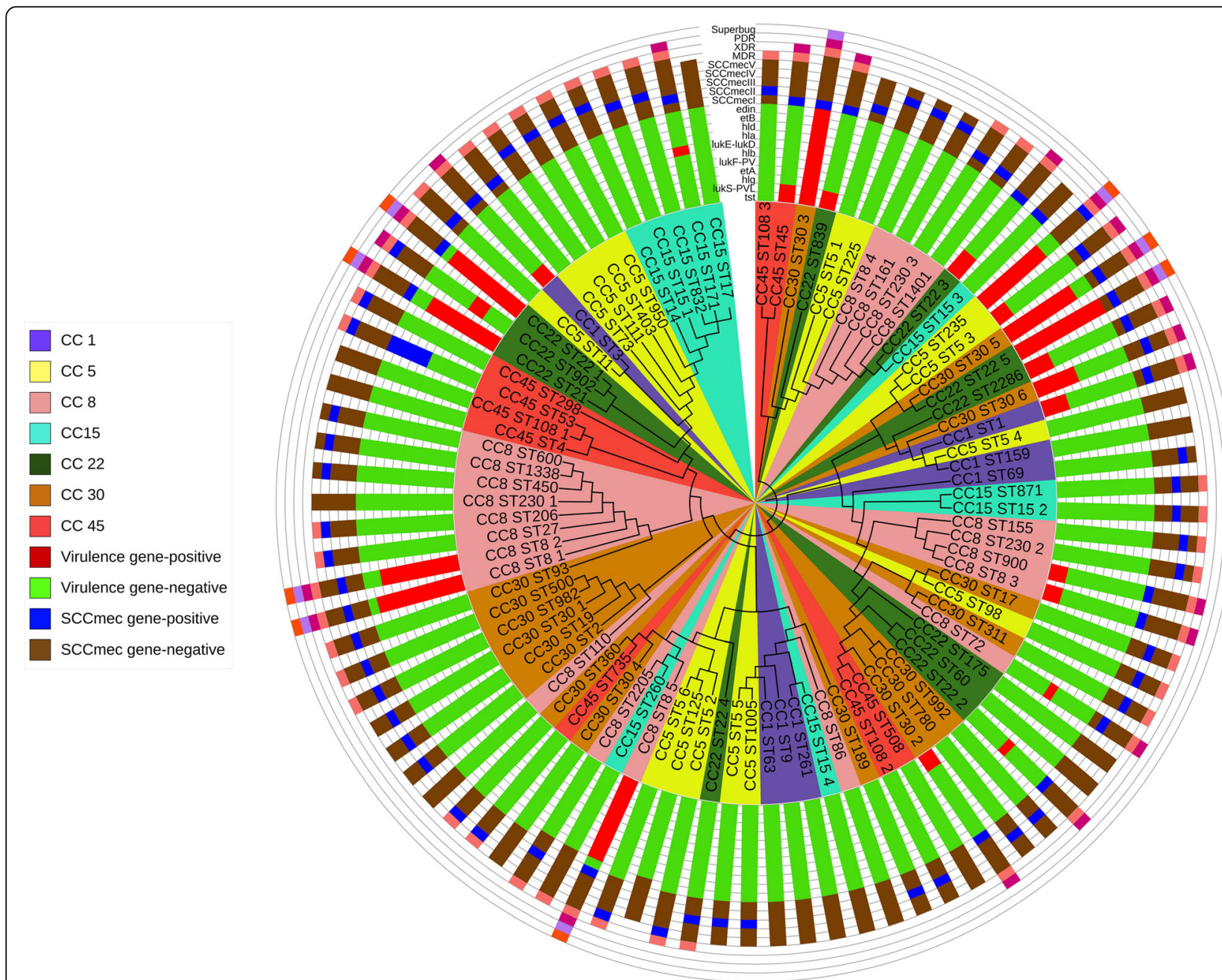

Fig. 2 The multi-locus sequence typing (MLST) phylogenetic tree, unrooted, maximum likelihood, and circular-dendrogram clustering of S. aureus based on sequence type (ST) profiles. The circular-dendrogram was estimated by neighbor-joining using the k2+ G model, with MEGA version 6 and Figtree version 1.4.4 
Table 2 Relationship virulence factors, antibiotic resistance and virulence, and $\beta$-lactamase regulatory genes in BSI collection of S. aureus

\begin{tabular}{|c|c|c|c|c|c|c|c|c|}
\hline \multirow{2}{*}{$\begin{array}{l}\text { Virulence factor } \\
\text { genes }\end{array}$} & \multicolumn{7}{|c|}{ Fold change of virulence and $\beta$-lactamase regulatory genes } & \multirow{2}{*}{$\begin{array}{l}\text { Antibiotic } \\
\text { resistance } \\
\text { profiles }\end{array}$} \\
\hline & $m e c R I$ & medl & mecA & blaZI & RNAIII & sarA & RNAII & \\
\hline tst ${ }^{* * *}$ & $<0.001$ & $<0.001$ & $<0.001$ & $<0.001$ & $<0.001$ & $<0.001$ & $<0.001$ & 0.034 \\
\hline etA & $<0.001$ & $<0.001$ & $<0.001$ & $<0.001$ & $<0.001$ & $<0.001$ & $<0.001$ & 0.695 \\
\hline$e t B$ & $<0.001$ & $<0.001$ & $>0.001$ & $<0.001$ & $<0.001$ & $>0.001$ & $<0.001$ & 0.074 \\
\hline lukS-PVL & $<0.001$ & $<0.001$ & $<0.001$ & $<0.001$ & $<0.001$ & $<0.001$ & $<0.001$ & 0.007 \\
\hline lukF-PV & $<0.001$ & $<0.001$ & $<0.001$ & $<0.001$ & $<0.001$ & $<0.001$ & $<0.001$ & 0.049 \\
\hline lukE-lukD & $>0.001$ & $<0.001$ & $<0.001$ & $<0.001$ & $<0.001$ & $<0.001$ & $<0.001$ & 0.014 \\
\hline edin $A$ & $>0.001$ & $<0.001$ & $<0.001$ & $<0.001$ & $<0.001$ & $<0.001$ & $<0.001$ & 0.019 \\
\hline $\mathrm{Hla}$ & $<0.001$ & $<0.001$ & $<0.001$ & $<0.001$ & $<0.001$ & $<0.001$ & $<0.001$ & 0.082 \\
\hline$H / b$ & $<0.001$ & $<0.001$ & $>0.001$ & $<0.001$ & $<0.001$ & $>0.001$ & $<0.001$ & 0.060 \\
\hline HId & $<0.001$ & $<0.001$ & $<0.001$ & $<0.001$ & $<0.001$ & $<0.001$ & $<0.001$ & 0.002 \\
\hline $\mathrm{Hlg}$ & $<0.001$ & $<0.001$ & $<0.001$ & $<0.001$ & $<0.001$ & $<0.001$ & $<0.001$ & 0.003 \\
\hline \multicolumn{9}{|l|}{$\mathrm{SCCmec}$ types } \\
\hline $\mathrm{sccmec}^{* *}$ & $<0.05$ & $<0.05$ & $<0.05$ & $<0.05$ & $<0.05$ & $<0.05$ & $<0.05$ & 0.004 \\
\hline sccmedl & $<0.05$ & $<0.05$ & $<0.05$ & $<0.05$ & $<0.05$ & $<0.05$ & $<0.05$ & 0.049 \\
\hline sccmeclll & $<0.05$ & $<0.05$ & $<0.05$ & $<0.05$ & $<0.05$ & $<0.05$ & $<0.05$ & 0.052 \\
\hline scCmedV & $<0.05$ & $<0.05$ & $<0.05$ & $<0.05$ & $<0.05$ & $<0.05$ & $<0.05$ & 0.040 \\
\hline \multirow[t]{2}{*}{ sccmecV } & $<0.05$ & $<0.05$ & $<0.05$ & $<0.05$ & $<0.05$ & $<0.05$ & $<0.05$ & 0.012 \\
\hline & $<0.05$ & $<0.05$ & $<0.05$ & $<0.05$ & $<0.05$ & $<0.05$ & $<0.05$ & 0.053 \\
\hline \multicolumn{9}{|c|}{ Antibiotic resistant strains } \\
\hline $\mathrm{MDR}^{*}$ & $<0.05$ & $<0.05$ & $<0.05$ & $<0.05$ & $<0.05$ & $<0.05$ & $<0.05$ & 0.009 \\
\hline XDR & $<0.05$ & $<0.05$ & $<0.05$ & $<0.05$ & $<0.05$ & $<0.05$ & $<0.05$ & 0.051 \\
\hline PDR & $<0.05$ & $<0.05$ & $<0.05$ & $<0.05$ & $<0.05$ & $<0.05$ & $<0.05$ & 0.069 \\
\hline
\end{tabular}

Asterisks indicate significant differences in gene expression levels between $\left({ }^{*}, P<0.05 ;{ }^{* *}, P<0.01 ;{ }^{* *}, P<0.001\right)$

\section{Discussion}

The study was conducted on MRSA and MSSA strains to determine the prevalence of VFs, SCCmec cassette, and regulation of virulence and $\beta$-lactamase gene expression in BSI isolates. The result revealed that the overall prevalence of penicillin and gatifloxacin resistant strains in S. aureus isolates 81.3 and $53.8 \%$, respectively. The linezolid $(8.79 \%)$ and amikacin $(12.0 \%)$ sensitive strains also were the most abundant. Similar findings were reported previously $[8,15]$.

In the current study, out of 61 MRSA strains, SCCmecI and SCCmecV, SCCmecII, SCCmecIII, and SCCmecIV genes were detected in $16.3,22.9,36.3$, and $21.3 \%$ of isolates. This finding was also reported by some researchers from South Africa [16], Saudi Arabia [17], and Venezuela [18]. Surprisingly, none of the MSSA strains carried the VF genes. Previous studies have demonstrated a significant relationship between VFs and the SCCmec cassette. These findings are replicated in the current study. However, this effect appears to be strain-dependent, as this positive correlation between virulence and SCCmec is not observed in all MRSA strains [19, 20].
Likewise, different virulence factors related to MRSA clonal lineages are presented in a study performed by Hamada et al. and Bhowmik et al., suggesting that MRSA harboring SCCmec type IV produce significantly more biomass under static conditions than SCCmec type I-III. Nevertheless, better biofilm formers and a high prevalence of VFs correspond to SCCmec type I-III rather than SCCmec type IV when dynamic conditions are used [21, 22]. However, Kim et al. noticed an association between SCCmec type IV or V and virulence factors. The high prevalence of such staphylococcal cassettes promotes $S$. aureus pathogenicity. Thus allowing the bacteria to persist in the environment [23].

Based on gene expression results, the expression of VFs regulatory genes (sarA, SaeRS, and RNAIII) in MDR, XDR, and PDR strains were higher than those in antibiotic-sensitive strains. There was also a strong correlation between the regulation of VFs and antibiotic resistance profiles. Moreover, up-regulation of RNAIII and sarA genes in MRSA strains was observed. These results reflect those of numerous studies that found the overexpression of RNAIII and sarA 
genes in the MRSA strains compared to the MSSA strains. They also found that the PII and PIII in MRSA strains play an essential role in pathogenicity [13, 24, 25]. The fold change of the SaeRS, RNAIII, and sarA genes in some $S C C m e c$ positive isolates showed the highest value in line with the discussed studies. More precisely, our results showed that down-regulation of RNAII gene in some $S$. aureus isolates; however, PIII and sarA decreased expressions of regulated genes was less than other genes.

In the present study, we found that VF genes were more abundant in MRSA strains than MSSA strains. Further, some isolates carrying all or many VF genes showed high expression of mecR, mecI, mecA, and blaZ genes. Some researchers from the USA [26], Korea [27], and United Kingdom [28] indicated a strong correlation between VFs and up-regulation of mecR and mecI genes. They also showed that some VFs of $S$. aureus, such as Panton-Valentine, must play essential roles in distributing SCCmec cassettes. Our studies also provide novel information on how $S$. aureus potentially uses a unique regulatory system to control the expression of its VFs.

In the present study, mecR, mecI, mecA, and blaZ had a variable expression in toxin and hemolysin-producing isolates. Also, down-regulation of $m e c R$ and $m e c A$ was observed in hemolysin non-producing isolates. In nontoxigenic and antibiotic-sensitive strains, mecI may play a direct role in the overexpression of $\beta$-lactamase regulatory genes. Regarding other reports, the complex role of mecRI in the pathogenicity of MRSA strains can be concluded. They also confirmed that the cooperation of VFs and regulating $\beta$-lactamase genes also play a critical role in increasing the pathogenicity of S. aureus isolates [15, 29-31].

In some research, expression of virulence factors regulatory has been reported to be modulated in the presence of inhibitory concentrations of antibiotics [27]. Our findings are in line with these data. These data suggest the increased level of RNAIII in strains lacking mecRI is due to an increase in SarA-mediated transcription of RNAIII. Further, these data confirm a direct linkage between central methicillin expressions and three major virulence regulators (SarA, SaeRS, and RNAIII) in $S$. aureus.

Our results showed a significant relationship between increasing the frequency of antibiotic-resistant strains and $a g r$ two-component system expression. Some studies have linked reduction in $a g r$ function with antibiotic tolerance, reduction in the antibacterial activity, and the development of the MRSA phenotype. These changes being described in association with agr type II in the Lee et al. study [32].

A study also linked agr group II polymorphism with poor responses to vancomycin therapy for patients with MRSA infections [19]. In several in vitro studies, the reduction of the agr function has been shown to favor the development of antibiotic resistance. It may confer a potential advantage in a hospital setting [12]. Deltahemolysin is a virulence factor regulated by agr: encoded by hld within the agr locus; it is a protein derived from the translation of RNAIII, the effector molecule of agr. Mutations in agr are associated with strongly impaired virulence in various infections with enhanced biofilm formation. Our findings are in line with these data.

In the current study, $\beta$-lactam regulatory genes were investigated in this regard and found to induce transcriptional up-regulation of SaeRS. Additionally, the SaeRS is vital in regulating $\beta$-lactamase genes in S. aureus infection, and the inactivation of SaeRS decreases virulence and resistance. The results would therefore side with the findings of Rapun-Araiz et al. [33]. They confirmed that the sae system regulates the expression of many virulence factors involved in bacterial adhesion, toxicity, and immune evasion.

Also, SaeRS two-component system activity is linked with the synthesis of virulence factors and virulence factor regulators, including RNAIII, part of the agr quorum-sensing system. However, it should be noted that in all these cases, the formation of biofilm is one of the most critical factors in increasing antibiotic resistance. In BSI, the SaeRS system was activated by the presence of human neutrophil peptides, calprotectin, $\mathrm{H} 2 \mathrm{O} 2$, an acidic $\mathrm{pH}$, and sub-inhibitory concentrations of $\beta$ lactam antibiotics [33, 34].

According to our observation in BSI isolates, dangerous isolates like ST295, ST30, and ST230 had a high expression level of virulence and $\beta$-lactamase regulatory genes. These STs have been frequently reported in BS infections, and increased antibiotic resistance levels have also been seen in this ST. However, ST15 and ST1 were identified as dangerous strains in South Korea reports [3] and Malaysia [35]. In this study, among 91 isolates, 64 unique STs were detected, and the ST30, ST5, and ST22 were the most common STs in S. aureus isolates. Moreover, the remaining six isolates were found to belong to ST30. Other reports described a collection of $S$. aureus isolates that commonly belong to ST30 and ST22 $[36,37]$. The NBJ tree of the ST30 gene included six isolates into one central cluster.

Regarding virulence genes, edin genes were detected in a single isolate of CC30. Several studies performed in different countries have been reported this toxin in other MRSA genetic backgrounds such as CC30 and C22 [15, 38]. This demonstrated consistency with the previous studies. CC30 and CC22 were the only clones that were positive for exfoliative toxins et $A$, et $B$ genes. These toxins are responsible for staphylococcal scalded skin syndrome $[38,39]$. The prevalence of these genes might be due to the specific geographic region. 
We hope to develop a more vital understanding of the virulence in MRSA and MSSA strains in the future. This knowledge may also help clarify the role of $\beta$-lactamase enzymes in the pathogenicity and VFs gene expression of $S$. aureus. Therefore, This data could also help investigate the pathogenicity differences between the MRSA and MSSA strains in BSI.

However, the two main limitations of the present study are the lack of biofilm operons and $\sigma$ factor. Twocomponent regulatory systems play a critical role in quorum-sensing and biofilm formation. Biofilm formation can also lead to antibiotic resistance in various bacteria. Also, the $\sigma$ factor plays an essential role in twocomponent regulatory systems. On the other hand, agrdependent and SaeRS-dependent systems are affected by the $\sigma$ factor. Although the role of $\sigma$ factor in antibiotic resistance is unclear, it is involved in pathogenicity.

\section{Conclusions}

We found a different activity of virulence and $\beta$ lactamase regulatory gene in MSSA and MRSA strains. A low expression of SaeRS, RNAIII, and sarA genes was observed in MSSA strains; however, virulence regulatory genes increased MRSA strains' virulence activity. However, the strong correlation between virulence and $\beta$ lactamase regulatory gene indicated that MRSA invasion could be reduced by suppressing any of these regulators. $S C C m e c$ cassette also plays a vital role in the pathogenicity and activity of PII and PIII promoters. S. aureus elaborates on many virulence factors that allow the organism to establish and spread infections under various conditions. The regulation of these virulence factors is intimately linked with antibiotic resistance by antibioticresistant regulators. The close linkage of the twocomponent system and virulence determinant can be exploited to modify the temporal pattern of virulence factor synthesis and attenuate virulence. In addition, increasing two-component system activity could potentially increase the susceptibility of $S$. aureus to bactericidal antibiotics in BSI. The expression of SaeRS and alternative agr locus and virulence promotors were demonstrated to be inducible by sub-inhibitory concentrations of methicillin and may thus be involved in this process. Further, the two-component system SaeRS was shown to play a crucial role in resistance against $\beta$ lactam antibiotics. Thus, understanding the risk factors associated with BSI can lead to preventive interventions to reduce complications, including mortality.

\section{Methods}

\section{Study design, collection, and identification of isolates}

Between January 2019 and February 2020 in Hamadan, 639 samples were collected from BSI isolates. These isolates were collected from teaching hospitals' microbiology laboratories in Hamadan city from Iran. All blood samples which were sent to the diagnostic microbiology laboratory were included in the study. After considering the Inclusion and Exclusion criteria, blood samples are used for culture and further biochemical investigations. Samples are inoculated in Blood Agar (Merck, Germany). Around 91 clinical isolates of S. aureus from BSI, which grew beta-hemolytic golden-yellow colonies on $5 \%$ sheep blood agar, were processed.

\section{Antimicrobial susceptibility testing}

The disk diffusion method (DDM) and the Clinical \& Laboratory Standards Institute (CLSI) guidelines were used for the screening of antibiotic susceptibility profiles [40]. The test was performed on Muller Hinton agar (Merck, Germany). For quality control, S. aureus ATCC 25923 and S. aureus ATCC 43300 were used.

\section{DNA extraction and detection of VFs genes}

DNA to be used as a PCR template was extracted from $S$. aureus isolates using a simple boiling method. Briefly, $S$. aureus isolates were grown overnight on LB agar. A single bacterial colony was re-suspended in $1000 \mu \mathrm{l}$ sterile water and centrifuged for $10 \mathrm{mins}$ at $13000 \mathrm{rpm}$ after vortexed. The supernatant was removed, and the pellet was re-suspended in $200 \mu \mathrm{L}$ of $10 \mathrm{mM}$ EDTA (pH 8) and vortexed, after incubated at $100{ }^{\circ} \mathrm{C}$ for $30 \mathrm{~min}$. After boiling, $100 \mu \mathrm{L}$ of $10 \mathrm{mM}$ Tris- $\mathrm{HC}(\mathrm{pH} 8)$ was added and centrifuged for $5 \mathrm{mins}$ at $13000 \mathrm{rpm}$ after vortexed. The resulting supernatant was used as a template for PCR [41]. Finally, by Nanodrop (Hangzhou, China), the DNA concentration was measured.

According to Table 3, the VFs, antibiotic resistance, and $\mathrm{SCCmec}$ genes were amplified. The Eppendorf PCR machine (Eppendorf, Mastercycler ${ }^{\circledR}$ 5332, Germany) was used for amplifying genes. The $25 \mu$ l reaction mixture contained $12.5 \mu \mathrm{l}$ of master mix (Ready Mix TM-Taq PCR Reaction Mix, Ampliqon, Denmark), $0.5 \mu \mathrm{M}$ concentration of each primer, $1 \mu \mathrm{l}$ of the genomic DNA template, and $11.5 \mu \mathrm{L}$ of molecular biology grade water. In each round of amplification, sterile water was used as a negative control.

\section{RNA extraction, synthesis of CDNA and qRT- PCR assay}

RNA extraction and cDNA synthesis were performed by GeneAll mini kit (GeneAll Biotechnology, Korea) [42]. Relative quantification was carried out using the Cycle Threshold (CT) comparative method. qRT-PCR reactions were performed in 96-well microplates (ABI-Step One-Plus) using the ABI-Step One-Plus Real-time System, ABI, USA. Components used for each reaction in q-PCR were $1 \mu \mathrm{l}$ aliquot of the first-strand cDNA in a final volume of $20 \mu \mathrm{l}$; containing $10 \mathrm{pM}$ of specific primers (forward and reverse) was used. PCR was carried 
Table 3 Primers used for identification of virulence factors genes, SCCmec types, real-time PCR of $\beta$-lactamase and virulence regulatory genes BSI collection of S. aureus

\begin{tabular}{|c|c|c|}
\hline Genes & Primers & Ref \\
\hline tst & $\begin{array}{l}\text { F: TTCACTATTTGTAAAAGTGTCAGACCCACT } \\
\text { R: TACTAATGAATIIIIITATCGTAAGCCCTT }\end{array}$ & [12] \\
\hline etA & $\begin{array}{l}\text { F: ACTGTAGGAGCTAGTGCATTTGT } \\
\text { R: TGGATACTITGTCTATCTITTCATCAAC }\end{array}$ & [12] \\
\hline$e t B$ & $\begin{array}{l}\text { F: CAGATAAAGAGCTTTATACACACATTAC } \\
\text { R: AGTGAACTTATCTITCTATTGAAAAACACTC }\end{array}$ & [12] \\
\hline lukS-PVL & $\begin{array}{l}\text { F: ATCATTAGGTAAAATGTCTGGACATGATCCA } \\
\text { R: GCATCAASTGTATTGGATAGCAAAAGC }\end{array}$ & [12] \\
\hline LuKE-LukD & $\begin{array}{l}\text { F: TGAAAAAGGTTCAAAGTTGATACGAG } \\
\text { R: TGTATTCGATAGCAAAAGCAGTGCA }\end{array}$ & [12] \\
\hline lukM & $\begin{array}{l}\text { F: TGGATGTTACCTATGCAACCTAC } \\
\text { R: GTTCGTITCCATATAATGAATCACTAC }\end{array}$ & [12] \\
\hline edinA & $\begin{array}{l}\text { F: GAAGTATCTAATACTTCTTIAGCAGC } \\
\text { R: TCATTGACAATTCTACACTTCCAAC }\end{array}$ & [12] \\
\hline hla & $\begin{array}{l}\text { F: CTGATTACTATCCAAGAAATTCGATTG } \\
\text { R: CTITCCAGCCTACTIIITITACAGT }\end{array}$ & [12] \\
\hline$h / b$ & $\begin{array}{l}\text { F: GTGCACTTACTGACAATAGTGC } \\
\text { R: GTTGATGAGTAGCTACCTTCAGT }\end{array}$ & [12] \\
\hline hld & $\begin{array}{l}\text { F: AAGAATTITATCTTAATTAAGGAAGGAGTG } \\
\text { R: TTAGTGAATTTGTCACTGTGTCGA }\end{array}$ & [12] \\
\hline$h / g$ & $\begin{array}{l}\text { F: GTCAYAGAGTCCATAATGCATTTAA } \\
\text { R: CACCAAATGTATAGCCTAAAGTG }\end{array}$ & [12] \\
\hline sccmed & $\begin{array}{l}\text { F: GCTTTAAAGAGTGTCGTTACAGG } \\
\text { R: GTTCTCTCATAGTATGACGTCC }\end{array}$ & {$[4]$} \\
\hline sccmedl & $\begin{array}{l}\text { F: CGTTGAAGATGATGAAGCG } \\
\text { R: CGAAATCAATGGTTAATGGACC }\end{array}$ & {$[4]$} \\
\hline sccmedll & $\begin{array}{l}\text { F: CCATATTGTGTACGATGCG } \\
\text { R: CCTTAGTTGTCGTAACAGATCG }\end{array}$ & {$[4]$} \\
\hline sccmedV & $\begin{array}{l}\text { F: GCCTTATTCGAAGAAACCG } \\
\text { R: CTACTCTTCTGAAAAGCGTCG }\end{array}$ & {$[4]$} \\
\hline sccmecV & $\begin{array}{l}\text { F: GAACATTGTTACTTAAATGAGCG } \\
\text { R: TGAAAGTTGTACCCTTGACACC }\end{array}$ & {$[4]$} \\
\hline mecRl & $\begin{array}{l}\text { F: TGGTATTGGGTTAGTGAA } \\
\text { R: GATTAGGTTAAGGCATTGA }\end{array}$ & [32] \\
\hline med & $\begin{array}{l}\text { F: AATGGCGAAAAAGCACAACA } \\
\text { R: GACTTGATTGTTCCTCTGTT }\end{array}$ & [32] \\
\hline blaz & $\begin{array}{l}\text { F: AAGAGATTTGCCTATGCTTC } \\
\text { R: GCTTGACCACTITTATCAGC }\end{array}$ & [33] \\
\hline mecA & $\begin{array}{l}\text { F: AAAGAACCTCTGCTCAACAAGT } \\
\text { R: TGTTATTTAACCCAATCATTGCTGTT }\end{array}$ & [33] \\
\hline RNAll & $\begin{array}{l}\text { F: TATGAATAAATGCGCTGATGATATACCACG } \\
\text { R: TITAAAGTTGATAGACCTAAACCACGACC }\end{array}$ & [34] \\
\hline RNAIII & $\begin{array}{l}\text { F: GCCATCCCAACTTAATAACCA } \\
\text { R: TGTTGTTTACGATAGCTTACATGC }\end{array}$ & [34] \\
\hline sarA & $\begin{array}{l}\text { F: TCTTGTTAATGCACAACAACGTAA } \\
\text { R: TCTTGTTAATGCACAACAACGTAA }\end{array}$ & [34] \\
\hline agrA & $\begin{array}{l}\text { F: ATGCACATGGTGCACATGC } \\
\text { R: GTCACAAGTACTATAAGCTGCGAT }\end{array}$ & [11] \\
\hline$a g r B$ & $\begin{array}{l}\text { F: ATGCACATGGTGCACATGC } \\
\text { R: GTATTACTAATTGAAAAGTGCCATAGC }\end{array}$ & [11] \\
\hline $\operatorname{agrC}$ & $\begin{array}{l}\text { F: ATGCACATGGTGCACATGC } \\
\text { R: CTGTTGAAAAAGTCAACTAAAAGCTC }\end{array}$ & [11] \\
\hline $\operatorname{agrC}$ & F: ATGCACATGGTGCACATGC & [11] \\
\hline
\end{tabular}


Table 3 Primers used for identification of virulence factors genes, SCCmec types, real-time PCR of $\beta$-lactamase and virulence regulatory genes BSI collection of S. aureus (Continued)

\begin{tabular}{lll}
\hline Genes & Primers & Ref \\
\hline \multirow{3}{*}{ seaRs } & R: CGATAATGCCGTAATACCCG \\
& F: GCTCATGCTTCTGAGCAAGA & R: CTAATACGACTCACTATAGGGAGA \\
gmk & F: TCGTTITATCAGGACCATCTGGAGTAGGTA & R: CATCTTAATTAAAGCTCAAACGCATCCC \\
\hline
\end{tabular}

out using $4 \mu \mathrm{l}$ 2x FIREPol Master Mix RTL MgCl2 Master Mix (Solis BioDyne, Tartu, Estonia), primer forward and reverse both were $0.5 \mu \mathrm{l}$, template cDNA $2 \mu \mathrm{l}$, and RNase free water $13 \mu \mathrm{l}$ to final volume $20 \mu \mathrm{l}$. The PCR protocol was designed for 40 cycles, and a melting-curve analysis $\left(65^{\circ} \mathrm{C}\right.$ to $95^{\circ} \mathrm{C}$, fluorescence read every $0.3^{\circ} \mathrm{C}$ ) was performed to check the specificity of the amplification. Relative quantification was achieved using the CT comparative method [43]. For quality control, S. aureus ATCC 25923 and S. aureus ATCC 43300 were used in the study.

\section{Generating heat maps of expression data}

For the drawing of the heatmap, the One Matrix CIM online package (https://discover.nci.nih.gov/cimminer/ home.do) was used. To obtain a preliminary overview of the gene expression data, all $\log _{2}$-fold changes generated by Bioconductor programmer DESeq2 (v1.14.1) for the test conditions compared to the control were input into the heatmap. 2 regardless of the adjusted $p$-value.

\section{Multi-locus sequence typing of isolates}

Multi-locus sequence typing (MLST) for S. aureus was performed, according to Tahmasebi et al. [15]. MLST of $S$. aureus was performed based on the sequences of seven housekeeping genes $\operatorname{arcC}$, aroE, glpF, gmk, pta, tpi, and yqiL (https://pubmlst.org/organisms/staphylococcusaureus). MLST database (https://pubmlst.org/bigsdb?db= pubmlst_saureus_seqdef\&page=profiles\&scheme_id=1) also used for the determination of STs.

\section{Statistical analysis}

All statistical analyses were performed using the Prism GraphPad, version 8.0 (GraphPad Software, Inc., CA, US). The relationship between categorical variables was compared using the $\chi^{2}$ test. Further analysis was performed in DataAssist (Applied Biosystems, CA, USA). The $p$-value was calculated based on a two-sample, twotailed Student's t-test for the calculated. Fold change (relative to the epilepsy group) and a p-value were generated on a two-sample, two-tailed Student's t-test. One Matrix CIM online package (https://discover.nci.nih.gov/ cimminer/home.do) was used for drawing the heatmap and hierarchical clustering. Expression analysis data were taken in three replication and given as mean value $\pm \mathrm{SE}$.

\section{Abbreviations}

VFs: Virulence factor; MRSA: Methicillin-resistant Staphylococcus aureus; SCCmec: Staphylococcal cassette chromosome mec; HA-MRSA: Associated with healthcare-associated MRSA; TSST-1: Toxic shock syndrome toxin 1; MDR: Multidrug-resistant; XDR: Extensively drug-resistant; PDR: Pandrugresistant; MLST: Multi-locus sequence typing; ST: Sequence type; CT: Cycle threshold

\section{Supplementary Information}

The online version contains supplementary material available at https://doi. org/10.1186/s12866-021-02257-4.

Additional file 1.

\section{Acknowledgments}

This article's authors are grateful to Hamadan University of Medical Sciences for their financial support in conducting the research. This work was supported by a research grant from Hamadan University of medical sciences (Grant/Award Number: 9510075757).

\section{Authors' contributions}

SD and BZ performed the tests, collected and analyzed the data, performed the analysis of the data.HT and SD contributed to design and project admiration. MRA designed the project and contributed to the whole steps of the project. All authors read and approved the final manuscript.

\section{Funding}

This work was supported by the Research Centre of Hamadan University of Medical Sciences on grant number 9510075757 . This funding's devoted just to purchasing materials which used in our study.

Availability of data and materials

The datasets used and/or analyzed during the current study are available from the corresponding author on reasonable request.

\section{Declaration}

Ethics approval and consent to participate

This study was approved by the Ethics Committee of Hamadan University of Medical Sciences (Code No: IRUMSHA. REC. 1395.757), about the consent to participate is not applicable.

\section{Consent for publication}

Not Applicable.

\section{Competing interests}

The authors declare that they have no competing interests.

\section{Author details}

${ }^{1}$ Microbiology Department, Faculty of Medicine, Hamadan University of Medical Sciences, Hamadan, Iran. ${ }^{2}$ School of Medicine, Shahroud University of Medical Sciences, Shahroud, Iran. ${ }^{3}$ Nutrition health Research center, Hamadan University of Medical Sciences, Hamadan, Iran. 
Received: 28 January 2021 Accepted: 13 June 2021

Published online: 25 June 2021

\section{References}

1. Tahmasebi H, Dehbashi S, Arabestani MR. Co-harboring of mcr-1 and $\beta$ lactamase genes in Pseudomonas aeruginosa by high-resolution melting curve analysis (HRMA): Molecular typing of superbug strains in bloodstream infections (BSI). Infect Genet Evol. 2020;1:104518. https://doi.org/10.1016/j. meegid.2020.104518.

2. Abraham L, Bamberger DM. Staphylococcus aureus bacteremia: contemporary management. Mo Med. 2020;117(4):341-5.

3. Park K-H, Greenwood-Quaintance KE, Uhl JR, Cunningham SA, Chia N Jeraldo PR, et al. Molecular epidemiology of Staphylococcus aureus bacteremia in a single large Minnesota medical center in 2015 as assessed using MLST, core genome MLST and spa typing. PLoS One. 2017;12(6): e0179003. https://doi.org/10.1371/journal.pone.0179003.

4. Maeda M, Shoji H, Shirakura T, Takuma T, Ugajin K, Fukuchi K, et al. Analysis of staphylococcal toxins and clinical outcomes of methicillin-resistant Staphylococcus aureus bacteremia. Biol Pharm Bull. 2016;39(7):1195-200. https://doi.org/10.1248/bpb.b16-00255.

5. Gu F, He W, Xiao S, Wang S, Li X, Zeng Q, et al. Antimicrobial resistance and molecular epidemiology of Staphylococcus aureus causing bloodstream infections at Ruijin Hospital in Shanghai from 2013 to 2018. Sci Rep. 2020; 10(1):6019. https://doi.org/10.1038/s41598-020-63248-5.

6. Etter D, Corti S, Spirig S, Cernela N, Stephan R, Johler S. Staphylococcus aureus Population Structure and Genomic Profiles in Asymptomatic Carriers in Switzerland. Front Microbiol. 2020;11:1289. https://doi.org/10.3389/fmicb.2 020.01289.

7. Planet PJ. Life After USA300: The Rise and Fall of a Superbug. J Infect Dis. 2017;215(suppl_1):S71-s7. https://doi.org/10.1093/infdis/jiw444.

8. Gurung RR, Maharjan P, Chhetri GG. Antibiotic resistance pattern of Staphylococcus aureus with reference to MRSA isolates from pediatric patients. Future science OA. 2020;6(4):FSO464. https://doi.org/10.2144/fsoa-2 019-0122.

9. Heydari N, Alikhani MY, Jalilian FA, Tahmasebi H, Arabestani MR. Evaluation of real time PCR for detection of clinical isolates of Staphylococcus aureus and methicillin-resistance strains based on melting curve analysis method. Koomesh. 2017;19(4):877-86.

10. Dehbashi S, Tahmasebi H, Zeyni B, Arabestani MR. The relationship between promoter-dependent quorum sensing induced genes and methicillin resistance in clinical strains of staphylococcus aureus. J Zanjan Univ Med Sci Health Serv. 2018;26(116):75-87.

11. Mina H, Soe AM, Atsushi F, Yukie M, Masato S, Nobumichi K. Prevalence and genetic characteristics of methicillin-resistant Staphylococcus aureus and coagulase-negative staphylococci isolated from Oral cavity of healthy children in Japan. Microb Drug Resist. 2019;25(3):400-7. https://doi.org/10.1 089/mdr.2018.0333.

12. Thompson TA, Brown PD. Association between the agr locus and the presence of virulence genes and pathogenesis in Staphylococcus aureus using a Caenorhabditis elegans model. Int J Infect Dis. 2017;54:72-6. https://doi.org/10.1016/j.jijid.2016.11.411.

13. Li L, Cheung A, Bayer AS, Chen L, Abdelhady W, Kreiswirth BN, et al. The global regulon sarA regulates $\beta$-lactam antibiotic resistance in methicillin-resistant Staphylococcus aureus in vitro and in endovascular infections. J Infect Dis. 2016;214(9):1421-9. https://doi.org/10.1093/infdis/ jiw386.

14. Rogasch K, Rühmling V, Pané-Farré J, Höper D, Weinberg C, Fuchs S, et al. Influence of the two-component system SaeRS on global gene expression in two different $<$ em $>$ Staphylococcus aureus $</$ em $>$ strains. J Bacteriol. 2006;188(22):7742-58. https://doi.org/10.1128/jb.00555-06.

15. Tahmasebi H, Dehbashi S, Jahantigh M, Arabestani MR. Relationship between biofilm gene expression with antimicrobial resistance pattern and clinical specimen type based on sequence types (STs) of methicillin-resistant S. aureus. Mol Biol Rep. 2020:47(2):1309-20. https://doi.org/10.1007/s11033019-05233-4.

16. Singh-Moodley A, Lowe M, Mogokotleng R, Perovic O. Diversity of SCCmec elements and spa types in south African Staphylococcus aureus mecApositive blood culture isolates. BMC Infect Dis. 2020;20(1):816. https://doi. org/10.1186/s12879-020-05547-w.

17. Albarrag A, Shami A, Almutairi A, Alsudairi S, Aldakeel S, Al-Amodi A Prevalence and molecular genetics of methicillin-resistant < i $>$ Staphylococcus aureus</i > colonization in nursing homes in Saudi Arabia. Can J Infect Dis Med Microbiol. 2020;2020:2434350. https://doi.org/10.1155/2 020/2434350

18. Bastidas $B$, Méndez MV, Vásquez $Y$, Requena D. Typification of the staphylococcal chromosome cassette of methicillin-resistant Staphylococcus aureus in the state of Aragua, Venezuela. Rev Peru Med Exp Salud Publica. 2020;37(2):239-45. https://doi.org/10.17843/rpmesp.2020.372.4652.

19. Tahmasebi H, Dehbashi S, Arabestani MR. Association between the accessory gene regulator (agr) locus and the presence of superantigen genes in clinical isolates of methicillin-resistant Staphylococcus aureus. BMC Res Notes. 2019;12(1):1. https://doi.org/10.1186/s13104-019-4166-7.

20. Firoozeh F, Omidi M, Saffari M, Sedaghat H, Zibaei M. Molecular analysis of methicillin-resistant Staphylococcus aureus isolates from four teaching hospitals in Iran: the emergence of novel MRSA clones. Antimicrob Resist Infect Control. 2020;9(1):112. https://doi.org/10.1186/s13756-020-00777-8.

21. Bhowmik D, Chetri S, Das BJ, Dhar Chanda D, Bhattacharjee A. Distribution of virulence genes and SCCmec types among methicillin-resistant Staphylococcus aureus of clinical and environmental origin: a study from community of Assam, India. BMC Res Notes. 2021;14(1):58. https://doi.org/1 0.1186/s13104-021-05473-3.

22. Hamada M, Yamaguchi T, Sato A, Ono D, Aoki K, Kajiwara C, et al. Increased incidence and plasma-biofilm formation ability of SCCmec type IV methicillin-resistant Staphylococcus aureus (MRSA) isolated from patients with bacteremia. Front Cell Infect Microbiol. 2021;11:602833. https://doi. org/10.3389/fcimb.2021.602833.

23. Kim HJ, Choi Q, Kwon GC, Koo SH. Molecular epidemiology and virulence factors of methicillin-resistant Staphylococcus aureus isolated from patients with bacteremia. J Clin Lab Anal. 2020;34(3):e23077. https://doi.org/10.1002/ jcla.23077.

24. Zielinska AK, Beenken KE, Mrak LN, Spencer HJ, Post GR, Skinner RA, et al. sarA-mediated repression of protease production plays a key role in the pathogenesis of Staphylococcus aureus USA300 isolates. Mol Microbiol. 2012;86(5):1183-96. https://doi.org/10.1111/mmi.12048.

25. Seidl K, Chen L, Bayer AS, Hady WA, Kreiswirth BN, Xiong YQ. Relationship of agr expression and function with virulence and vancomycin treatment outcomes in experimental endocarditis due to methicillin-resistant Staphylococcus aureus. Antimicrob Agents Chemother. 2011;55(12):5631-9. https://doi.org/10.1128/AAC.05251-11.

26. Watkins RR, David MZ, Salata RA. Current concepts on the virulence mechanisms of meticillin-resistant Staphylococcus aureus. J Med Microbiol. 2012;61(Pt 9):1179-93. https://doi.org/10.1099/jmm.0.043513-0.

27. Uddin MJ, Ahn J. Associations between resistance phenotype and gene expression in response to serial exposure to oxacillin and ciprofloxacin in Staphylococcus aureus. Lett Appl Microbiol. 2017;65(6):462-8. https://doi. org/10.1111/lam.12808.

28. Rudkin JK, Laabei M, Edwards AM, Joo HS, Otto M, Lennon KL, et al. Oxacillin alters the toxin expression profile of community-associated methicillin-resistant Staphylococcus aureus. Antimicrob Agents Chemother. 2014:58(2):1100-7. https://doi.org/10.1128/aac.01618-13.

29. Lakhundi S, Zhang K. Methicillin-Resistant <span class=\&quot;namedcontent genus-species\&quot; id=\&quot;named-content-1\&quot; $>$ Staphylococcus aureus</span>: Molecular Characterization, Evolution, and Epidemiology. Clin Microbiol Rev. 2018;31(4):e00020-18. https://doi.org/1 0.1128/CMR.00020-18.

30. Rasheed NA, Hussein NR. Characterization of different virulent factors in methicillin-resistant Staphylococcus aureus isolates recovered from Iraqis and Syrian refugees in Duhok city, Iraq. PLoS One. 2020;15(8):e0237714. https://doi.org/10.1371/journal.pone.0237714.

31. Alli OA, Ogbolu DO, Shittu AO, Okorie AN, Akinola JO, Daniel JB. Association of virulence genes with mecA gene in Staphylococcus aureus isolates from Tertiary Hospitals in Nigeria. Indian J Pathol Microbiol. 2015;58(4):464-71. https://doi.org/10.4103/0377-4929.168875.

32. Lee SO, Lee S, Lee JE, Song K-H, Kang CK, Wi YM, et al. Dysfunctional accessory gene regulator (agr) as a prognostic factor in invasive Staphylococcus aureus infection: a systematic review and meta-analysis. Sci Rep. 2020;10(1):20697. https://doi.org/10.1038/s41598-020-77729-0.

33. Rapun-Araiz B, Haag AF, Solano C, Lasa I. The impact of two-component sensorial network in staphylococcal speciation. Curr Opin Microbiol. 2020;55: 40-7 https://doi.org/10.1016/j.mib.2020.02.004.

34. Mainiero M, Goerke C, Geiger T, Gonser C, Herbert S, Wolz C. Differential Target Gene Activation by the <em $>$ Staphylococcus aureus $</$ em $>$ Two- 
Component System <em>saeRS</em\&gt. J Bacteriol. 2010;192(3):613. https://doi.org/10.1128/JB.01242-09.

35. Sit PS, Teh CSJ, Idris N, Sam IC, Syed Omar SF, Sulaiman H, et al. Prevalence of methicillin-resistant Staphylococcus aureus (MRSA) infection and the molecular characteristics of MRSA bacteraemia over a two-year period in a tertiary teaching hospital in Malaysia. BMC Infect Dis. 2017;17(1):274. https:// doi.org/10.1186/s12879-017-2384-y.

36. Monteiro AS, Pinto BLS, Monteiro JM, Ferreira RM, Ribeiro PCS, Bando SY, et al. Phylogenetic and Molecular Profile of Staphylococcus aureus Isolated from Bloodstream Infections in Northeast Brazil. Microorganisms. 2019;7:7. https://doi.org/10.3390/microorganisms7070210.

37. Xiao N, Yang J, Duan N, Lu B, Wang L. Community-associated Staphylococcus aureus PVL(+) ST22 predominates in skin and soft tissue infections in Beijing, China. Infect Drug Resist. 2019;12:2495-503. https://doi. org/10.2147/idr.s212358.

38. Shettigar K, Murali TS. Virulence factors and clonal diversity of Staphylococcus aureus in colonization and wound infection with emphasis on diabetic foot infection. Eur J Clin Microbiol Infect Dis. 2020;39(12):223546. https://doi.org/10.1007/s10096-020-03984-8.

39. Lebeurre J, Dahyot S, Diene S, Paulay A, Aubourg M, Argemi X, et al. Comparative genome analysis of Staphylococcus lugdunensis shows clonal complex-dependent diversity of the putative virulence factor, ess/type VII locus. Front Microbiol. 2019;10:2479. https://doi.org/10.3389/fmicb.2019.02479.

40. Performance Standards for Antimicrobial Susceptibility Testing: 30nd Informational Supplement CLSI M100-S30. Wayne, PA: CLSI; 2020.

41. Dehbashi S, Tahmasebi H, Arabestani MR. Association between beta-lactam antibiotic resistance and virulence factors in $\mathrm{AmpC}$ producing clinical strains of P. aeruginosa. Osong Public Health Res Perspect. 2018;9(6):325-33. https://doi.org/10.24171/j.phrp.2018.9.6.06.

42. Dehbashi S, Pourmand MR, Alikhani MY, Asl SS, Arabestani MR. Coordination of las regulated virulence factors with multidrug-resistant and extensively drug-resistant in superbug strains of P. aeruginosa. Mol Biol Rep. 2020;47(6): 4131-43. https://doi.org/10.1007/s11033-020-05559-4.

43. Pfaffl MW. A new mathematical model for relative quantification in real-time RT-PCR. Nucleic Acids Res. 2001;29(9):e45. https://doi.org/10.1093/nar/29.9.e45.

\section{Publisher's Note}

Springer Nature remains neutral with regard to jurisdictional claims in published maps and institutional affiliations.

Ready to submit your research? Choose BMC and benefit from:

- fast, convenient online submission

- thorough peer review by experienced researchers in your field

- rapid publication on acceptance

- support for research data, including large and complex data types

- gold Open Access which fosters wider collaboration and increased citations

- maximum visibility for your research: over $100 \mathrm{M}$ website views per year

At $\mathrm{BMC}$, research is always in progress.

Learn more biomedcentral.com/submissions 